in contrast to the case of 5-methoxy-8-hydroxy-flavone, in which 5-methoxygroup was readily hydrolysed. These results conform very well with Asahina's view.

For partial demethylation $\mathrm{AlCl}_{3}$ in $\mathrm{CS}_{2}$ proved to be suitable reagent in this case. Dimethoxyflavone $(1 \mathrm{~g}), \mathrm{AlCl}_{3}(2 \mathrm{~g})$ and dry $\mathrm{CS}_{2}(30 \mathrm{cc})$ were boiled gently on a water-bath for 20 hrs. By decomposing the reaction-product with $\mathrm{HCl}$ and ice crude 5-hydroxy-8-methoxy-flavone was obtained, which was purified from alcohol, forming sulphuryellow needles of m.p. $210^{\circ}$, which was not depressed when admixed with primetinmonomethylether. Yield $0.5 \mathrm{~g}$. Gives green $\mathrm{FeCl}_{3}$-test. $\left(\mathrm{C}_{16} \mathrm{H}_{12} \mathrm{O}_{4}\right.$ requires C 71.62, H 4.51; Found 71.25, H 4.56).

Acetyl-derivative: Colourless needles from alcohol. Melts at $176^{\circ}$, alone or admixed with acetyl-mono-methyl-primetin $\left(\mathrm{C}_{18} \mathrm{H}_{14} \mathrm{O}_{5}\right.$ requires $\mathrm{C} 69.65, \mathrm{H} 4.54$; Found $\left.\mathrm{C} 69.51 \mathrm{H} 4.49\right)$.

1) W. Nagai, S. Hattori: J. Chem. Soc. Japan 1930, 162.

2) S. Sugasawa : J. chem. Soc. 1933, 1621.

3) W. Baker : J. chem. Soc. 1934, 1953.

4) S. Sugasawa: this Journal 56, 105.

5) K. Nakazawa : this Journal 59, 196.

6) W. Baker: J. chem. Soc. 1939, 956.

7) K. Okalaki : this Journal 59, 190, (also compare Asahina and Yoshioka : Ber 1936, 1367).

8) R. C. Shah: J. chem. Soc. 1938, 8555.

\title{
Über Meso-Methyltetradecylbernsteinsäure.
}

\author{
von
}

Mitizo Asano und Traki Azumi

[Aus d. Pharmz. Institut, Medical College Kanazawa].

(Eingegeangen am 11. September 1939.)

Früher haben wir durch Reduktion von Dihydro-protolichesterinsäure mittels Jodwasserstoffsäure eine Methyltetradecylbernsteinsäure vom Fp $133-135^{\circ}$ erhalten ${ }^{1)}$,

1) Ber. 68, 991 [1935]. 
die Asano u. Ohta ${ }^{2)}$ aus Tetradecyljodid und Propan- $\alpha, \alpha, \beta$-tricarbonsäureester synthetisiert. Kondensiert man nun $\alpha$-Brompalmitinsäureester mit Natrium-methyl-malonester, so crhält man Heptadecantricarbonsäure, die beim Erhitzen decarboxyliert und zur Methy'ltetradecylbernsteinsäure übergeht. Dic letztere schmilzt aber bei $98-101^{\circ}$. Die früher crhaltene höher-schmelzende Methyltetradecyl-bernsteinsäure ist also Para-Säure (Fumaroid-Form) und die jetzt dargestellte tieferschmelzende Meso- oder anti-Säure (Maleinoid-Form) aufzufassen. Die erstere ist in Eisessig schwer löslich, dagegen ist die letztere darin leicht löslich. Beim Erhitzen von Meso-Säure im Rohr mit Salzsäurc auf $190-200^{\circ}$, findet jedoch keine Umwandlung zur Para-Säure statt.
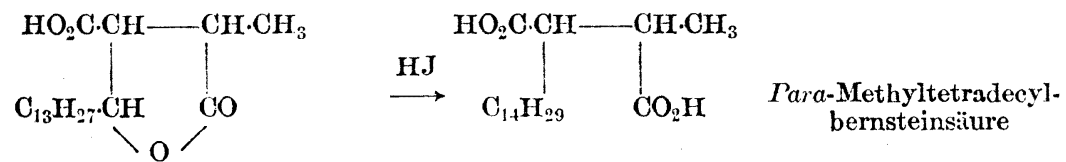

Dihydroprotolichesterinsïure
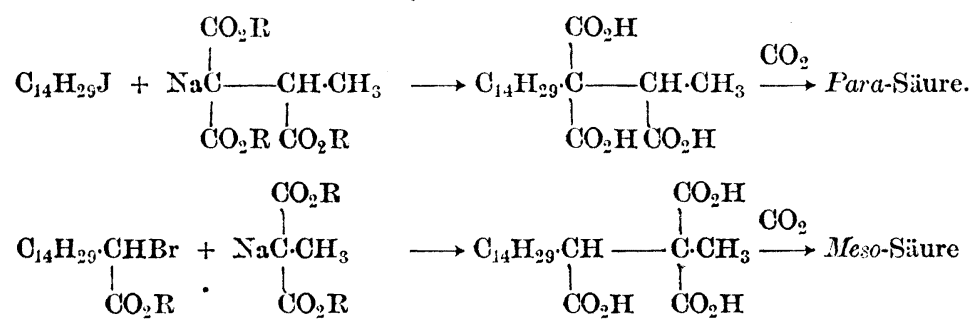

\section{Heptadecan-2,2,3-tricarbonsäure.}

Werden $9 \mathrm{~g}$ Methylmalonester (mit $1.2 \mathrm{~g}$ Natrium und $15 \mathrm{cc}$ absolut. Alkohol und $18 \mathrm{~g}$ a-Brompalmitinsäureäthyl im Rohr auf $130-140^{\circ} 9 \mathrm{Stdn}$. erhitzt, so werden $18 \mathrm{~g}$. Reaktionsprodulit vom $\mathrm{K}_{4} 220-230^{\circ}$ crhalten, die mittels alkoholiches Kalis verseift werden. Krystallinisches Pulver vom $\mathrm{Zp.} 127^{\circ}$ (aus Eisessig).

$$
\begin{aligned}
& \mathrm{C}_{20} \mathrm{H}_{36} \mathrm{O}_{6} \text {. Ber. } \quad \text { C } 64.47, \quad \text { H } 9.74, \quad \text { Mol.-Gew. 372.3. } \\
& {\left[\mathrm{C}_{1} ; \mathrm{H}_{33}(\mathrm{COOH})_{3}\right] . \quad \text { Gef. C } 64.58 \text {, H } 9.88 \text {, Mol.-Gew. } 373.3 \text {. }}
\end{aligned}
$$

\section{Meso- $\alpha$-Methyl- $\alpha^{\prime}$-tetradecylbernsteinsäure.}

$2 \mathrm{~g}$ Heptadecantricarbonsäure werden auf $130-140^{\circ}$ erhitzt. Nach 3 stündigem Erhitzen wird das l'rodult mit alkoholischem Kali verseift. Der in Petroläther

2) Ber. 67, 1842 [19:44]. 
schwer lösliche Teil wird aus Eisessig wiederholt umgelöst. Farbloses Nädelchen vom $\mathrm{Fp} 98-101^{\circ}$.

\begin{tabular}{|c|c|c|c|c|}
\hline${ }_{66} \mathrm{O}_{4}$ & & & & \\
\hline
\end{tabular}

\title{
Über die Bestandteile von Nephromopsis Stracheyi f. ectocarpisma Hue (III. Mitteil.) $)^{1)}$
}

\author{
von
}

Mitizo Asano u. Masami Tanigutr

[Aus d. Pharmazeut. Institut d. Medical College Kanazawa].

(Eingegangen am 11. September 1939.)

- Früher haben Asano und Azumi ${ }^{2}$ aus der Flechte Nephromopsis Stracheyi f. ectocarpisma Hue neben Nephromopsinsäure und l-Lichesterinsäure eine B-Säure genannte Substanz isoliert, deren endgültige Reinigung ihnen nicht gelang. Jetzt konnten wir aus der B-Säure durch Chromatographieren mittels des Aluminiumoxyds (standardisicrt nach Brockmann die l-Protolichesterinsäure (Fp 103-106 ${ }^{\circ},[a]_{1}^{10}-12.4^{\circ}$ ) herauszubringen. Nämlich wird die letztere, als die am leichtesten adsorbierbare Substanz unter den drei genannten Bestandteilen, am obersten Teil des Adsorbierendesmittel festgehalten. Bei der Einwirkung von Diazomethan auf der so gereinigten l-Protolichesterinsäure crhielten wir das Pyrazolin-Derivat $\mathrm{C}_{21} \mathrm{H}_{36} \mathrm{O}_{4} \mathrm{~N}_{2}$ (Fp 60-61 , $\left.[a]_{D}^{12}-288.2^{\circ}\right)$. Dics bestätigt die Resultate von Asano und Kanematsu ${ }^{3}$ ), stimmt aber

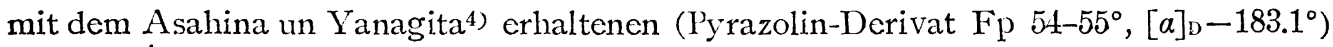
nicht überein.

(Autoref.)

1) I. Mitteil. M. Asano u. T. Azumi : Ber. 68, 995 [1985].

II Mitteil. M. Asano u. T. Azumi: Ber. 72, 35 [1939].

2) Ber. 68, 995 [1935].

3) Ber. 65, $1178[1932]$.

4) Ber. 69, 124 [1936]. 


\title{
Meso・メチルテトラデチル琥珀酸に就て
}

\author{
淺野 三千三 \\ 安住千秋
}

\section{（金澤醫科大學附屬藥學專門部）}

（昭和 14 年 9 月 12 日受理)

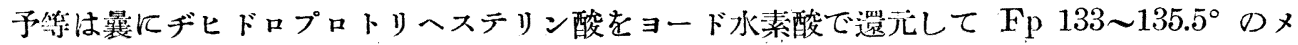

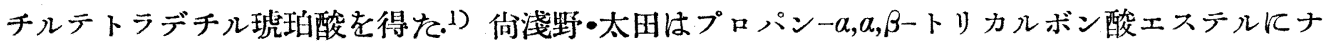
トリウムの存在でテトラデチルョーヂドを作用させて 134 ～ $136^{\circ}$ のメチルテトラデチル琥珀酸 を得たが゙うそのアニリドはノルカペラート酸を脫水脫岑酸した後ョード水素酸で還元して得ら れる二監基性酸のアニリド3)と全く一致した。

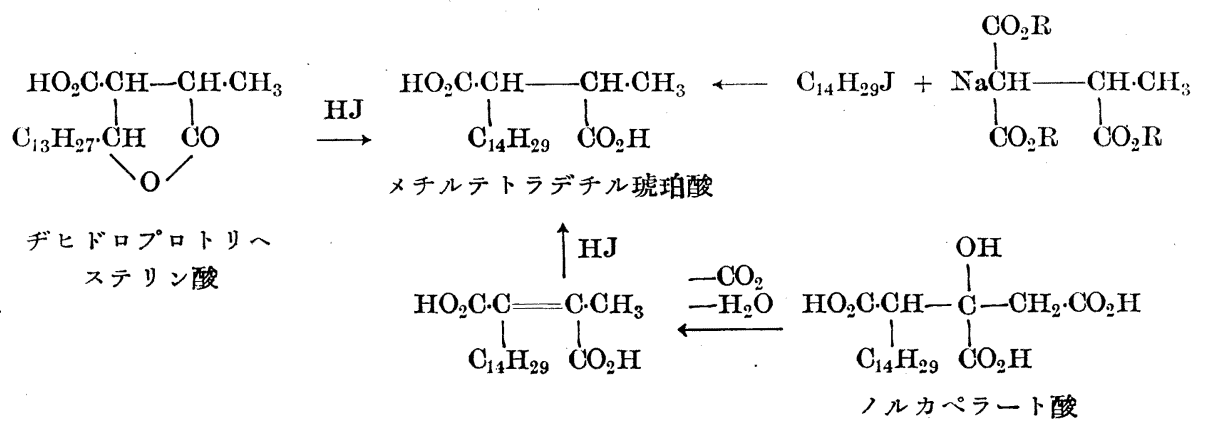

然ると今包 $a$-ブロムパルミチン酸エステルにナトリウムメチルマロンエステルを作棜させて 得られるへプタデカントリカルボン酸を加熱して脫炭酸を行つたとてろ其成績體 $\mathrm{C}_{19} \mathrm{H}_{36} \mathrm{O}_{4}$ は 當然メチルテトラデチル琥珀酸でなければならないのに其融點は 98〜101で再三再絬晶を繰 这しても融點に變化はなかつた。

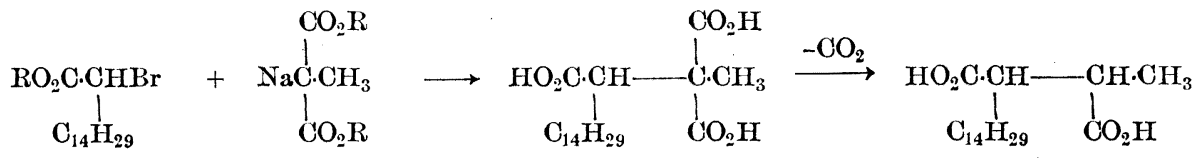

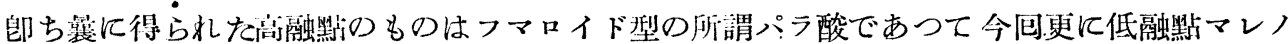

\footnotetext{
1) 本誌 55, 811 〔昭 10〕

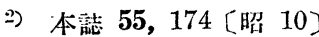

3) 本誌 54, 145 [昭 9]
} 
イド型のメジ酸(アンチ酸)が發見されたわけである，们パラ酸は氷醋に難溶であるがメジ酸は

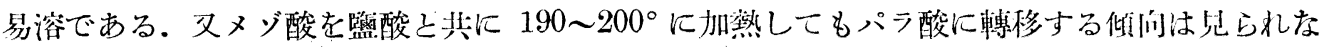
かつた。

本研究費肪の補助を仰いだ日本與術振興會飞對し深謝する。

\section{實 驗 の 部}

\section{a-Brompalmitinsäureester と Methylmalonester との作用}

a-Brompalmitinsäureäthylester 三頸コルベン中にパルミチン酸 $50 \mathrm{~g}$ と赤燐 $4 \mathrm{~g}$ とをよく混 和し之に乾燥ブロムを徐々に滴下寸れば盛にブロム水素を發生して反應する. 全量 $100 \mathrm{~g}$ のブロムを加一終 りて油浴中に 70 90 に加熱すれ徐徐々にブロム水素を發生して反應する.5 時間加熱してから更に $20 \mathrm{~g}$

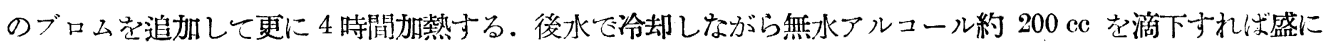
ブロム水素を發生して反應する. 之を水浴上に 1 時間加熱し冷後水中に注ぎ析出する赤褐色油狀の物質を

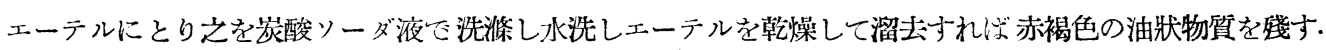

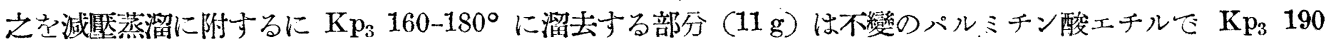
〜200 に溜去寸る部分 $(47 \mathrm{~g})$ は $\alpha$-ブロムパルミチン酸エチルである4).

Heptadecan-2,2,3-tricarbonsäure. ボンベン管中に無水アルュール $15 \mathrm{cc}$ を入れ金曒ナトリウ ム $1.2 \mathrm{~g}$ 定溶解させ之にメチルマロン酸エチル $9 \mathrm{~g}$ を加へよく反應せしめてから

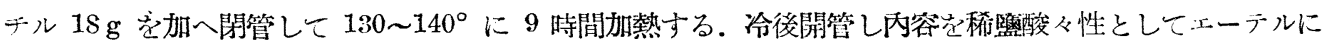

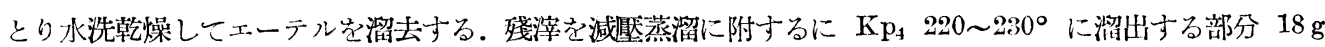
を得た。茲に得られるトリカルボン酸エチルエステルを 10\% アルコール性カリ $100 \mathrm{cc}$ と共に水浴上に

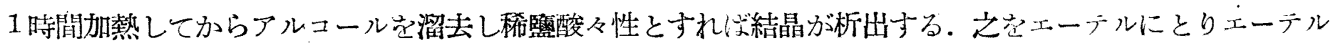

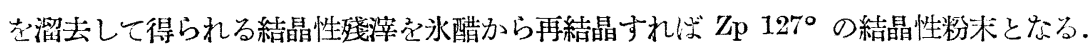

試料 $4.337 \mathrm{mg}$ : $\mathrm{CO}_{2} 10.27 \mathrm{mg}, \mathrm{H}_{2} \mathrm{O} 3.83 \mathrm{mg}$.一試料 $45.5 \mathrm{mg}$ : $3.66 \mathrm{cc} \mathrm{n} / 10-\mathrm{KOH}$.

$$
\begin{array}{cccccccc}
\mathrm{C}_{20} \mathrm{H}_{36} \mathrm{O}_{6} & \text { 計算值 } & \mathrm{C} & 64.47, & \mathrm{H} & 9.74, & \text { 分子量 } & 372.3 . \\
{\left[\mathrm{C}_{17} \mathrm{H}_{33}(\mathrm{COOH})_{3}\right]} & \text { 實驗值 } & \mathrm{C} & 64.58, & \mathrm{H} & 9.88, & \text { 分子量 } & 373.3 .
\end{array}
$$

\section{Meso-a-Methyl- $a^{\prime}$-tetradecylbernsteinsäure.}

Heptadecan-2,2,3-tricarbons:̈ure $2 \mathrm{~g}$ を油浴中 130 140 に加熱与るに盛に胲泡して熔融与る、3時間加

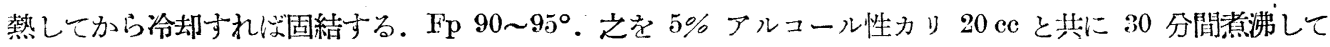
無水酸を分解してから稀監酸々性とすれ結晶が析出する，之きエーテルにとりエーテルを溜去する．残

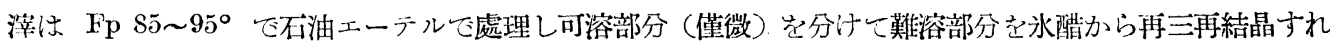
心 Fp 9S 101の小針狀晶が得られる. 更にメタノールから再結晶しても融點が上乐しない. 本品はメチ

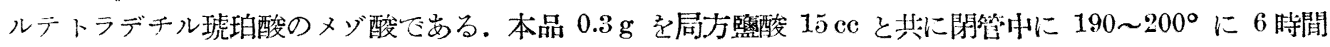
加熱しても融點の上舁が認められなからた。

試料 $4.094 \mathrm{mg}$ : $\mathrm{CO}_{2} 10.33 \mathrm{mg}, \mathrm{H}_{2} \mathrm{O} 4.12 \mathrm{mg}$.一試料 $46.8 \mathrm{mg}$ : $5.67 \mathrm{cc} \mathrm{n} / 20 \mathrm{KOH}$.

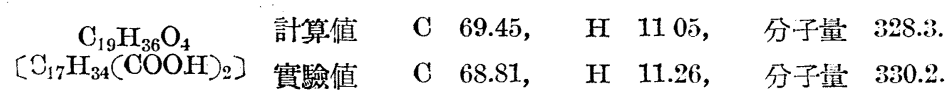

4) Ber. 24, 938, 2225 [1891]參照. 